IJ§ER

ISSN: 2149-5939
International Journal of Social Sciences and Education Research

Online, http://dergipark.gov.tr/ijsser

Volume: 3(3), 2017

\title{
Tekrarlar, “1 Yapıt=9 Yapıt” 1
}

\author{
Repeats, "1 Artwork=9 Artworks"
}

Figen Girgin²

Received Date: 02 / 02/ 2017

Accepted Date: 31 / 05/ 2017

$\ddot{O} z$

"Tekrarlar, 1 Yapıt=9 Yapıt" adlı bu araştırmada, Piet Mondrian tarafindan resmedilmiş bir modern sanat yapıtı olan Broadway Boogie Woogie çerçevesinde, sanatçıların neden tekrarlama gereği duydukları sorusuna yanıt aranmaya çalışılmıştır. Bu süreçte, bu yapıtı tekrarlamak için seçen 9 sanatçının eserine yer verilmiş ve bu eserler üzerinden tekrarlama eyleminin nedenleri ve gerekçeleri üzerine bir değerlendirme yapılmıştır. Bu araştırma, nitel araştırma yöntemlerinden betimsel tarama modeline göre gerçekleştirilmiş olup; araştırma konusu ile ilgili elektronik ortamda ve yazılı ve basılı her türlü kaynak taraması yapılmıştır.

Anahtar sözcükler: Tekrar, Yineleme, Yeniden Üretim, Çağdaş Sanat, Mondrian

\begin{abstract}
In this research called "Repeats, 1 Artwork $=9$ Artworks", question why artists need repetition was tried to be answered in the framework of Broadway Boogie Woogie, a work of modern art portrayed by Piet Mondrian. In this process, given the work of nine artists who choose to repeat this work and an evaluation was made on the reasons for the repetition with these works. This research was carried out according to the descriptive research model of qualitative research methods; The research topic was searched in electronic environment and all kinds of written and printed sources.
\end{abstract}

Keywords: Repeat, Say over, Reproduction, Contemporary Art, Mondrian

\section{Giriş}

Tekrarlamak basitçe, bir öğrenmenin gerçekleşmesini sağlayan ya da kalıcılığını arttıran bir eylemdir. Örneğin yüzme, dil, araba sürmek gibi şeyleri öğrenmek ya da öğrendiklerimizi kalıcı hale getirmek için tekrarlamaya ihtiyaç duyarız. Ancak bu durum, sanata gelindiğinde biraz değişiyor. Sanatçıların özellikle modern döneme kadar olanların, gezdikleri müze, inceledikleri heykellerden yola çıkarak yaptıkları çizimlerde çoğunlukla, tekrarlamak için seçilen o yapıtı özel kılan şeyin ne olduğu merakı, gözü eğitme isteği, beceri kazanma amacı gibi sebepler, bir sanatçıyı o yapıtı tekrarlamaya iter. İşte burada tekrar, sanatın içine tıpkı insanın sosyal yaşamında olduğu gibi ‘öğrenme’ amacı ile girer. Oysa modern sanatta izleri görülmeye başlayan ve çağdaş sanatta etkinliğini arttıran tekrarlama eyleminin altında çok nadiren böyle bir sebep yatar. Bir yapıt, farklı dil, anlam, teknik ve üslupla dile getirilmekte, aynı olan farklı ifadelerle yenilenmekte. Bu bilinçli tekrarlama sürecinde sanatçı işe, seçimle başlar. Bir yapıtı, kendi düşünce süzgecinden geçirmek için seçmek, aslında sanatçının o yapıtla bir yerde kurduğu bağ, benzer iç dünyasına sahip olma ya da farklı bir hesaplaşma içine girmek için onun uygun olması türden ilişkiler ağına sahiptir. Yaşadığımız çağda o kadar çok benzer ile karşılaşıyoruz ki, sanat-

\footnotetext{
${ }^{1}$ Bu araştırma, 27-29 Nisan 2017 tarihleri arasında Roma'da düzenlenmiş olan "ICSSER 3.International Conference on Social Sciences and Education Research" adlı konferansta sözlü bildiri olarak sunulmuştur

${ }^{2}$ Dr., Trakya Üniversitesi Eğitim Fakültesi Güzel Sanatlar Eğitimi Bölümü Resim-İş Eğitimi Anabilim Dalı, Edirne/TÜRKIYE, ffff_g@hotmail.com
} 
taki bu andırış ve benzer üzerinden farklılaşma eylemi de kaçınılmaz oluyor belki de. Ya da çağdaş sanatın daha çok söz söyleme çabası, yapıtları tekrarlamanın altında yatan sebeplerden birine dönüşüyor.

Her sanatçının bir birey olarak farklı bir yaşam ve sanat süzgecinden geçtiğini düşünürsek; bir yapıt ile başlayan seçimlerin birebir aynısı (kopya) olmadığı sürece farklı bir eser ile sonuçlanması da şaşırtıcı olmasa gerek. Araştırmada, kaynak yapıtın uğradığı değişimi, sanatçıların bir yapıtı seçme nedenlerini, bir yapıt üzerinden farklı neler söylediklerini daha iyi anlayabilmek için Mondrian'ın 'Broadway Boogie Woogie' adlı yapıtı temel alınmış ve bu yapıtı tekrarlayan farklı sanatçıların eserlerine yer verilmiştir.

\section{Broadway Boogie Woogie ve Tekrarlar}

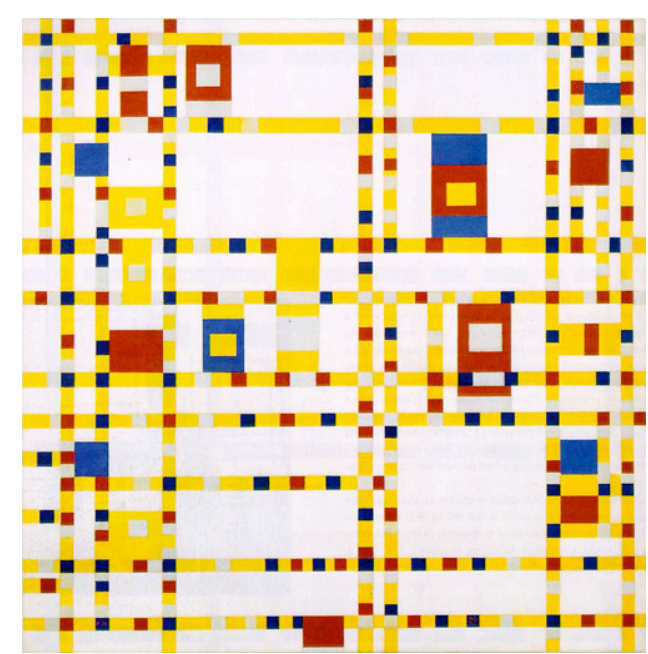

Resim 1. Piet Mondrian, Broadway Boogie Woogie, 1942-43,

Tuval üzerine yağlıboya, 127x127 cm, Modern Sanatlar Müzesi, New York

Kaynak ya da ana yapıt olarak seçilen Piet Mondrian'ın Broadway Boogie Woogie adlı yap1tına baktığımızda ilk olarak belirli renklerden oluşan dikey ve yatay çizgiler ile karşılaşmaktayız. Dikey ve yatay çizgiler, ana renkler, köşeli biçimler, Mondrian'ın (1872-1944) resimlerini oluşturan ana unsurlardır. Mondrian'ın resimleri, soyut sanatın en önemli niteliklerini gösterir. Lynton (1982:217)'un da ifade ettiği gibi: “bu sanat 'sanki' ya da 'evvel zaman içinde' gibi düşüncelere yer vermez. Her resim sadece kendisidir ve sürekli olarak şimdiki zaman içinde varlığını sürdürür”.

Resimleri onun ilgi alanı ile paralel olarak şekillenen sanatçının, 19.yy sonlarındaki yapıtlarında natüralizm ve empresyonizm etkileri, 20.yy başında Paris'te kaldığ y1llarda Kübizm etkileri görülürken, 1930'lu yılların sonu ve 1940'l yılların ortalarında Londra ve New York'ta kaldığı dönemde ise bu iki kentin, özellikle New York'un onun sanatındaki farklıllı̆ı ve değişimi beraberinde getirdiğini görmekteyiz.

Sokakların düzeni ve müzik, onun diğer resimlerine göre daha büyük ölçüde olan Broadway Boogie Woogie'yi resmetmesinde etkili olur. Resimde boşluğun ortada arttığı, küçük renk alanlarının sağ ve solda adeta tuvalin dışına çıkmak istercesine sıkışmanın olduğu belirgin olarak görülür. Bu resim, Lynton'un (1982:217-218) da ifade ettiği gibi, “Amerika'nın büyüklügünü, New York’un kalabalıklığını, canlılığını, trafiğgin hareketliliğini, elektrik lambalarını, müziğin, 
cazın ritmini yansıtır gibidir. Bu resim, onun Avrupa resimlerine göre daha az kişisellik yüklüdür, ruhsal ve fiziksel anlamda insana daha uzak bir görünümdedir”.

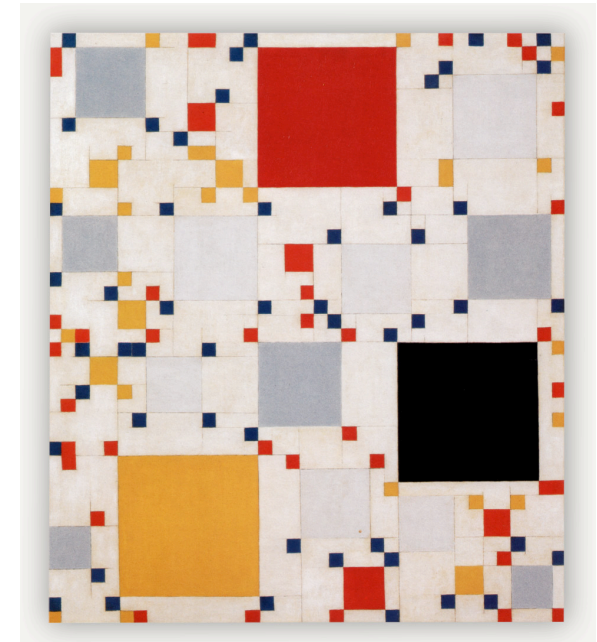

Resim 2. Leon Polk Smith, Victory Boogie-Woogie'ye Sayg1 1, 1946, Tuval üzerine yağlıboya, 106.9 x 94 cm., Dallas Sanat Müzesi, Texas

Mondrian'ın resimleri ile etkileşime giren Leon Polk Smith (1906-1996) çağdaş Avrupalı sanatçıların geometrik anlayışta yapılmış resimleri ile ilk kez okulda tanışmış, sonra da Albert E.Gallatin Sanat Galeri'sindeki Mondrian resimleri ilgisini çekmiştir. Smith, her ne kadar onun resimlerinin arka planında yatan felsefi tavra ikna olmamış olsa da Mondrian'ın estetik anlayışı, onu derinden etkilemiştir. Danto'ya göre Smith'in arayışı De Stijl grubunun diğer üyelerinin ve Mondrian'ın saplantılı olduğu düşünsel, teorik yaratıcı süreçten ziyade, sezgisel kararlardan oluşmaktaydı (Buck, 2006).

Smith'in Mondrian'a saygısını sunduğu ilk resmi Victory Boogie-Woogie'dir. Başlangıçta Mondrian'ın düz çizgileri ve köşeleri belirgin olan formlarını kullanan sanatçı, sonraki işlerine eğri formları da sokmuştur. Smith, Mondrian'dan etkilenme ve kendi olma sürecini şöyle açıklar:

“...o yalnızca düz bir çizgi veya direkt bir açıyı kullanmış olmasına rağmen, onun form ve mekânın öğelerinin değişiminin (ön-arka plan) keşfini kullanmanın harika olacağını düşünüyorum. Birisi eğrisel formu kullanacağı bir yol bulabilirse...Ben kesinlikle bir spor kataloğunda buldum. Teorik şekiller ve çizgiler çok sınırlıydı ve hemen kendimi bulmaya başlamak zorunda kaldım. Ama sonrasında resimde daha önce görmediğim mekânı burada yarattım. Düzdü ve aynı zamanda eğimliydi. Bir küre gibiydi. Düzlemler her yöne hareket ediyor gibiydi...Düşündüm de belki bir tondo üzerinde olduğundandır. Bunun doğru olup olmadığını bulmak zorundaydım. Görmek için dikdörtgen üzerine bir şeyler yapmalıydım...ve yaptım. Yani kavisli bir yüzeye sahip görünen dikdörtgen üzerine bir resim yapmak heyecan vericiydi. Kendi kendime yaptığım ilk önemli adımdı ya da sanata katkısı olandı" (Parks, 1986, ss.26-27).

Smith'in bu tekrarının temeli, her ne kadar Mondrian'ın Victory Boogie-Woogie adlı yapit1na dayanıyor olsa da o, sanat yaşamının temelinde Mondrian'ın yapıtlarını, özellikle 1930'lu yılların sonu ve 1940'lı yıllardaki olanlarını, biçim olarak özümsemiş bir sanatçıdır. O, kendisinin de ifade ettiği gibi, Mondrian'ın dikey ve yatay çizgilerine bazen eğrileri sokmuş bazen ise sadece eğriler ile hareket etmiştir. Onun bu yapıtı ise, Mondrian'ın aynı adlı yapıtı ve Broadway 
Boogie Woogie arasında bir yerdedir. Yüzeyde köşeli geometrik düzende açık renk değerlerini kullanarak Broadway Boogie Woogie'deki boşluğu yakalarken, tuvalin kenarlarına taşıdığı s1kışmış gibi duran küçük geometrik yapı ile de bu resmi çağrıştırırken; kullandığı büyük parçalı geometrik yapı ise Victorie Boogie-Woogie'nin ruhunu taşımaktadır.

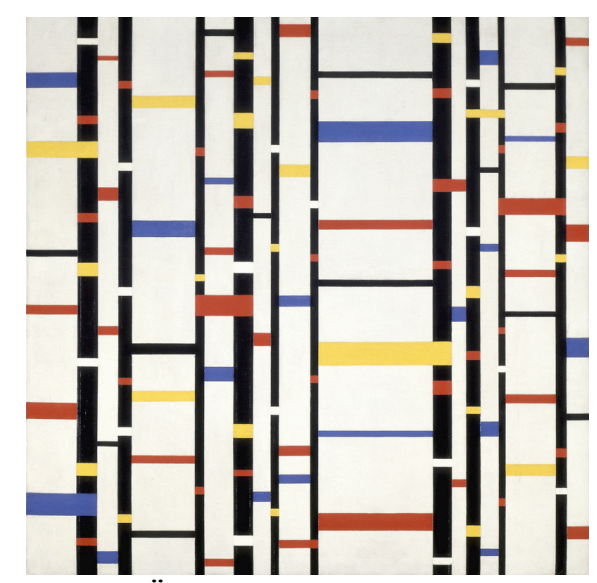

Resim 3. Burgoyne Diller, Üçüncü Tema, 1946-8, Tuval üzerine yağlıboya, $107 x 107 \mathrm{~cm}$, Whitney Amerikan Sanat Müzesi, New York, May Walter bağış1

Burgoyne Diller (1906-1965) ise De Stijl'i ve Mondrian'ın sanatsal anlayışını benimseyen ilk Amerikalı sanatçılardan biridir. Mondrian, doğadaki eğrilerin yerine yatay ve dikey çizgileri ve bu çizgilerden oluşan geometrik bir yapıyı, ana renkler dışında siyah ve beyazın kullanımını benimsemişti. Oysa Diller, yatay ve dikey çizgilerin ve bu denli aynılığın kullanılmasından endişe duymaktadır (Whitney Museum of American Art, Collection, tarihsiz). Mondrian'da çapraz veya üst üste gelmeyen dikdörtgenleri Diller reddeder. O, De Stijl'in sıkı kurallarında değişime gitmiştir. Mondrian'1 ve De Stijl'i benimseyen bu sanatçılar ile Mondrian, New York’ta kaldığ yıllarda tanışır. Mondrian onlara önderlik ederken, onlar da Mondrian'ın New York'taki resimlerini etkilemişlerdir. Aslında bu süreçte ortaya çıkan resimler, Prinz'in de ifade ettiği gibi bir anlamda karşılıklı etkileşimin ürünüdür (Prinz, tarihsiz).

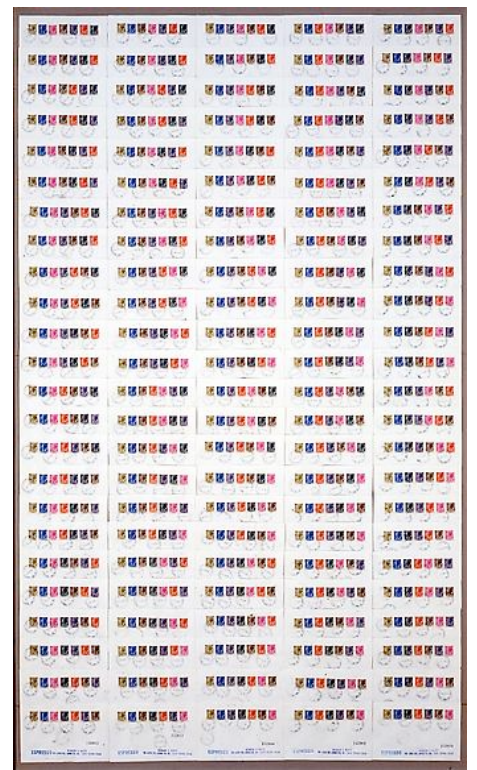

Resim 4. Alighiero Boetti, İsimsiz- Victory Boogie Woogie, 1972, 5042 zarf, 35.280 pul, 42 panel, 156,8x94,9 cm 
Girgin, F. (2017). Repeats, "1 Artwork=9 Artworks". International Journal of Social Sciences and Education

Research, 3(3), 803-816.

Diller, resimlerini üç grupta kategorize etmektedir. İlk Tema (The First Theme) 1zgara yapısı olmaksızın düzenlenmiş dikdörtgenler, İkinci Tema (The Second Theme) 1zgaraları oluşturmak için araya geçen dikdörtgenlerden oluşmaktadır. Bu resmin de yer aldığı Üçüncü Tema (The Third Theme) 'da ise formlar detaylı bir ızgara yapısını oluştururlar. Bu resimde siyah arka plan, mükemmele yakın simetri, az oranda kırmızı ve sarının kullanıldığı görülür. Bu, Diller'in son dönem işlerinin genel özelliğidir. Daha önceki yapıtlarında arka planın çoğunlukla beyaz renkte olduğu görülmektedir.

Alighiero Boetti (1940-1994) ise, Mondrian'nn Broadway Boogie Woogie'den sonra resmettiği ve bu resmin izlerini taşıyan Victory Boogie-Woogie adlı resminden yola çıkarak 7 İtalyan pulunun sıralamasında yer değişimi yaparak, yeni bir görsellik elde etmiştir. Onun posta çalışmalarının yapısal çerçevesini gündelik yaşam ve eylemler oluşturmaktadır. Izgara şeklinde dizilmiş bu renkli pullar, dekoratif bir görüntü ve güzel bir görsellik sunar. Onun çalışmaları için Francesco Clemente: "Bu beceriler ve etkinlikler meditasyon olabilir...günlük etkinlikleri yap1landırmak ve ölçmek için tekrarlanan eylemler" der (Sperone Westwater Press Release, tarihsiz, Alighiero...).

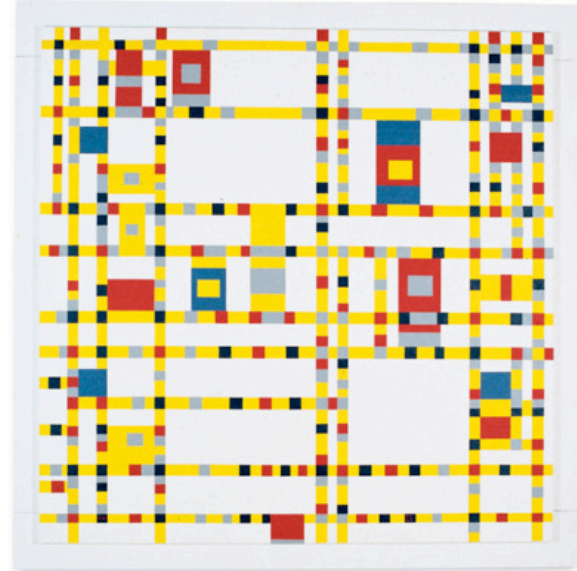

Resim 5. Tom Sachs, Victory Boogie Woogie, 1996, Bant ve kontrplak, $179.705 \times 179.705 \mathrm{~cm}$

Tom Sachs'ın (1966 -) Victory Boogie Woogie adını verdiği bu çalışma ise Mondrian'ın Broadway Boogie Woogie resminin koli bantları ile yapılmış bir taklididir. Sachs, Mondrian'a hayranlık duymaktadır ve bu hayranlığın neticesinde birçok Mondrian resmi yapmıştır. Ancak o, bu eserleri sahtekârlık olarak nitelendirmez. Bu doğrultuda; Mondrian'a olan hayranlığını ve yaptığını, Mondrian'ın resimlerinden farklı kılan şeyin ne olduğunu ifade ettiği sözlerine yer vermek yerinde olacaktır:

"Okulu bıraktığım zamanlarda gerçekten bir Piet Mondrian resmi istedim. Fakat onlar milyonlarca dolardı...yaşamımda ödün vereceğim bir şey yapmaya gerçekten istekli değilim. Ne tür bir uzlaşmaya hazırım? Benim karar verdiğim taviz, özgünlük oldu. Bir Mondrian'a sahip olmak benim için çok önemliydi, sonra Mondrian tarafından resmedilmiş bir tanesine. Bu nedenle ben bir uygulama yaptım. Bunu sahtecilik olarak tanımlamayacaktım çünkü yağlıboya kullanmamıştım. Onun yerine koli bandı kullandım. Veya ben şöyle demeliyim: Bir ressam değilim, heykeltıraşım. Bu nedenle o, bir resmin heykelidir. Koli bandı kullandım, hemen hemen her rengi olduğu için. Ve o, işsizlik ve ekonomi için Amerika'nın hoşgörüsüzlüğünü temsil eder...sevdiğim bu sanatla zamanımın çoğunu harcadım ve sonunda onun en iyi resimlerinin 
bir düzinesini yaptım, Broodway Boogie'yi de içeren. Mondrian'ın eserleri ile samimi bir zaman geçirdim, evlerinde ya da müzelerde onun eserlerine sahip olup da meslekleri ile meşgul olan insanlardan daha fazla" (Enright\&Walsh, 2014).

Aslında Sachs'ın sözleri, onun yaptı̆̆ 1 Mondrian kopyalarının altında yatan sebebin hayranlık olduğunu çok iyi özetler nitelikte. Bir sanatçının, bir başka sanatçının yapıtına ya da yapıtlarına duyduğu hayranlık, onu tekrara iter. Ancak burada onun kendi ile bir iç hesaplaşması da söz konusudur. Özgünlüğünden taviz vermeyi kabul ederek çıktığı bu yolda, kendini bir sahtekâr olarak nitelendirmez Sachs. Bunu da resmin orijinalinden farklı bir malzeme ile tekrarlamasına bağlar. Sachs'ın bir yapıta olan hayranlığı, geçmiş dönem (modernden önce) sanatçılar ile benzerdir. Bu hayranlığı onlarınki ile ortak kılan şey beğeni ile gelen seçim iken; farklı kılan şey ise bir öğreti ya da o yapıtı çözümleme temeline dayandırılmamış olmasıdır. En azından, onun sözlerinden anlaşılan budur.

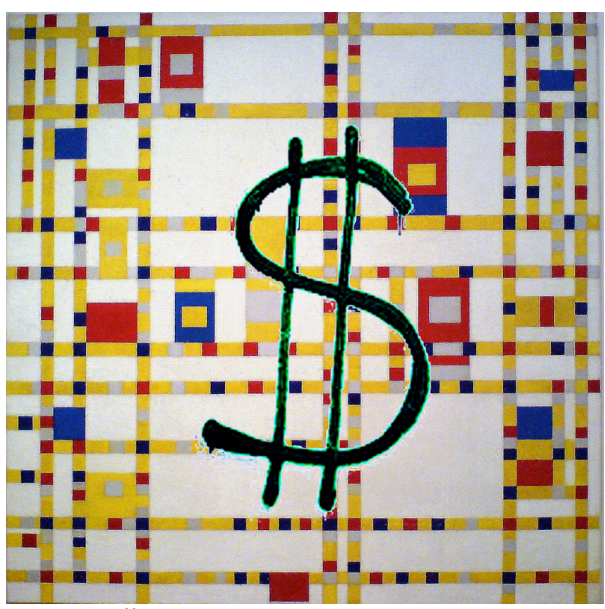

Resim 6. Serkan Özkaya, Broadway Boogie Woogie, 1997

Mondrian'ın yapıtını tekrarlayan sanatçılardan bir diğeri olan Serkan Özkaya (1973 -) ise 26 Kasım 1997'de, Alexander Brener'in 1997'deki eyleminden esinlenerek MOMA'ya kurumlarında bulunan "Broadway Boogie Woogie" resmine dolar işareti ile spreyleme yapma isteğini belirten bir yazı yazmıştır. Ayrıca bu dilekçesinde projesine destek olunması adına; Christo, Joseph Kosuth, Braco Dmitrijevic, Keith Arnatt gibi çağdaş sanatçıların isimlerini vererek, onlara benzer bir tavırda bir iş yapmak istediğini ve projesi için MOMA'nın kendisine bir kopya bulmalarını rica ettiğini de yazmıştır. MOMA'dan kendisine 16 Aralık 1997'de gelen cevap yazısında; Alexander Brener'in eylemini canice bulduklarını ve sanat eserine saygisı olan herkes için iğrenç olduğunu belirtmişlerdir. Ayrıca MOMA, Brener'in vandalizmine olumlu yönde dikkat çekilmesine de karşıdır ve Özkaya'dan projesini yeniden gözden geçirmesini ve işinde Brener'den esinlendiğine yer vermemesini belirtmişlerdir.

Mona Lisa'yı ters çevirip sergileme işinde de olduğu gibi Özkaya, orijinal ve kopya arasındaki sorunsalı ve modern dehanın kaybına karşı hem bir kutlama hem de üzülme içinde olduğu ikircikli tavrını gündeme getirmektedir. Sanatçı, bu işinde Brener'in merkez (ler)deki kapitalin çevreye ait bir üretimi meta anlamında nasıl sahiplendiğine yönelik eleştirisine herhangi bir göndermede bulunmaz. Geriden takip etme tavrını, sadece batılı eserler ile sınırlandırmaz, zamansal fark ilişkisini batı dışından bir eserle de kurabilmektedir (Kortun\&Kosova, 2007). 


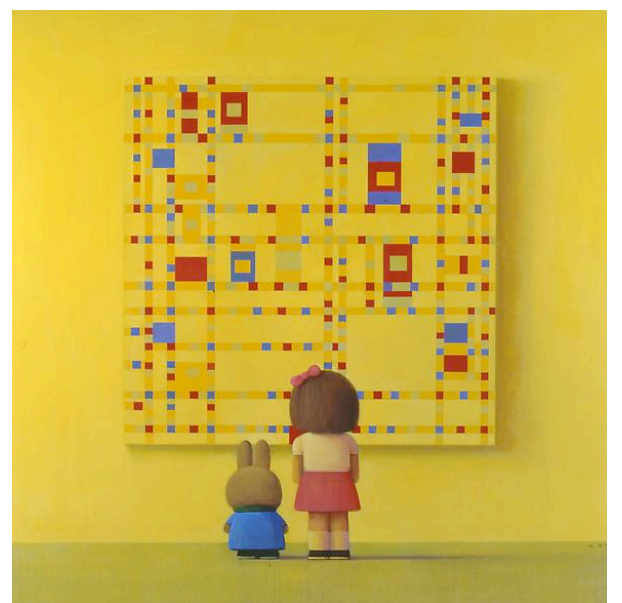

Resim 7. Liu Ye, Bir Zamanlar Broadway’de, 2006, Tuval üzerine akrilik ve yağlıboya, $210,2 \times 210,2 \mathrm{~cm}$, Özel Koleksiyon

Dick Bruna'nın çizgi karakteri, dişi tavşanı, Liu Ye'nin (1964 -) resimlerinde sıklıkla karş1mıza çıkar. Resimlerinde bunun dışında Hollanda sanatı, pop kültürü, Mondrian'ın etkileri belirgin olarak gözlemlenmektedir. Genellikle mekânda tek başına duran figür, kendi hikâyesini yazar. Dengeli kompozisyonlar, ışıklı ve saf renkler onun resimlerini özetler. Renk ve firça kullanımında Vermeer'in, geometri ve rasyonelliği ele alışında Mondrian'ın etkileri görülmektedir. Onun Vermeer ve Mondrian'a hayranlığ 1990'larda Hollanda'da kaldığ1 yıllarda oluşmuştur. Onun resimleri kendisinin de ifade ettiği gibi belli bir alt yapıya sahiptir. O da Mondrian'ın resimlerinden kaynak almaktadır. Resimlerinin ana yapısı dikeyliktir. Kendisini soyut bir ressam olarak tanımlamayan sanatçı; "Vermeer'in bir resmine baktığınızda onun ana yapısı Mondrian'ınkilerle aynıdır veya tam tersi Mondrian'ınkiler Vermeer'inkilerle aynıdır” der. Figürlere veya hikâyeye bakmadığınız zaman, yalnızca kompozisyon ve soyut öğeler aynıdır. Çinli bir sanatçı olmasına rağmen, Flaman ressamlar Mondrian ve Vermeer'i kendi sanatından daha yakın hissetmektedir. Çağdaşı olan birçok Çinli sanatçı politik konulara eğilirken o, sadece resmetmeyi yeğlemiştir. Bu durumu Kris Wilton ile yaptığı röportajda şöyle ifade eder:

"Politika benim neslim için çok önemli. Birçok sanatçı Mao, Coca Cola ve buna benzer şeyler resmediyor. Bir sanatçı bunu gerçekten konuşmak isterse, tamam. Fakat bu benim için önemli değildir. Ben daha çok resmin dili ve sanat ile ilgileniyorum. 100 y1l önce kötü bir politik sistem vardı fakat iyi sanat vard1... Sanat bir silah değildir" (Wilton, 2009).

Ye'nin sözlerinden de anlaşıldığı gibi onun resimlerinde birçok Çin'li sanatçının aksine politika etkin olarak yer almaz. Onun Bir Zamanlar Broadway resmine dönersek, dişi tavşanla birlikte küçük vücutlu figürlerinden biri Mondrian'ın resmi önünde durmuş, bakarken görülmektedir. Onun bu karakterleri genellikle bir Mondrian resminin önünde dururken görülür. Figürlerine eşlik eden Mondrian resimleri, sanatçı tarafından "dengeli, zarif ve saf" bir nesne olarak tanımlanmaktadır. (Sperone Westwater Press Release, tarihsiz, Liu Ye...). Felsefe ve masalın birlikte harmanlandığı bu resimleri basitçe bir doğu batı karması olarak görmek yanlış olur. Bu resimler, açıkça tanınabilir görüntünün yıkıcı espri ve belki de saçmalık gibi görünen unsurlarla yan yana getirilmesi ile onun sanatsal diline dönüşür. 


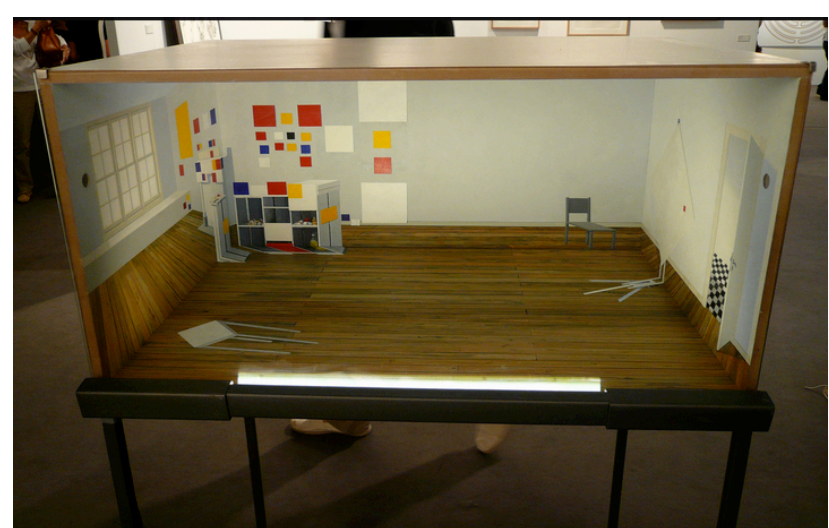

Resim 8. George Hadjimichalis, New York’ta Piet Mondrian'ın Stüdyosu, 2006, Ahşap, akrilik, cam, elektrik devresi kutusu

George Hadjimichalis (1954 -) ise birçok Mondrian tekrarından farklı olarak onun resmini üç boyuta taşır. New York'ta Piet Mondrian'ın Stüdyosu adlı bu çalışmasında, Mondrian'ın resimleri ile ilgili bir dvd'ye, Mondrian'ın çizimlerine yer vermiş ve bu görselde görüldüğü gibi onun stüdyosunun bir temsilini yapmıştır. Anamorfik perspektif kullanarak gerçekleştirdiği çalışmaya izleyicilerin içeri doğru bakmaları için iki delik açmıştır. Delikten içeri bakan izleyici için iki boyutlu mekân, birden üç boyutlu görünüme kavuşur.

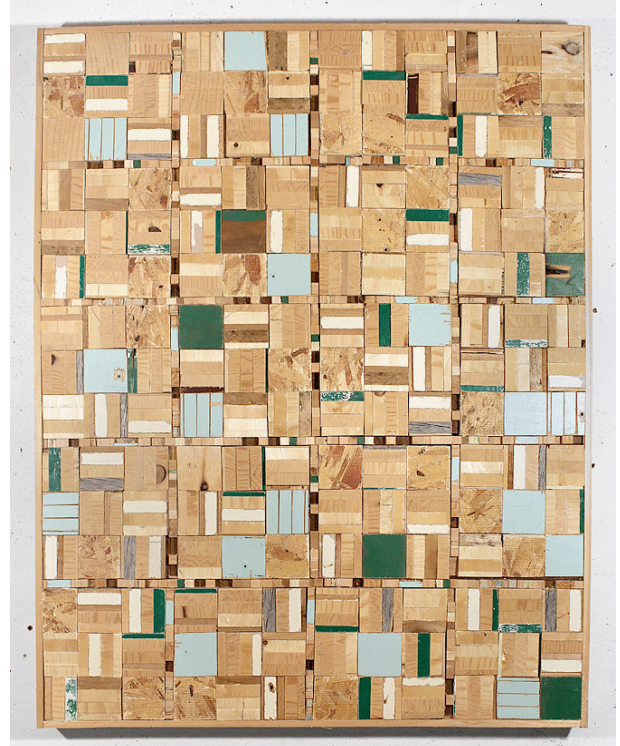

Resim 9. Aaron S.Moran, Karayolları ve İki Yönlü Yollar (Piet Mondrian’ın Broadway Boogie Woogie'sinden Sonra, 2015, Kontrplak, yeniden kullanılmış ahşap, kırmızı sedir, $75 x$ 57,5cm

Farklı malzeme kullanarak Mondrian'ın bu resmini tekrarlayan sanatçılardan bir diğeri de Aaron S.Moran'dır. Bu heykelinin de yer aldığı Pave Paradise (Asfalt İle Kaplanan Cennet) serisindeki eserler adlarını "onlar cenneti asfalt ile kapladılar ve otopark açtılar" sözleriyle ifade ettiği Joni Mitchell'in "Büyük Sarı Taksi" sinden alır. Bu çalışmanın da olduğu bu heykeller, kentsel / (alt) kentsel gelişmenin üç aşamasına değinen malzemelerden oluşur: kırmızı sedir, kontrplak ve yeniden kullanılmış ahşap. Kırmızı sedir, 'doğal' çevreye (ağaçlar, ormanlar, vb.), 
Girgin, F. (2017). Repeats, "1 Artwork=9 Artworks". International Journal of Social Sciences and Education Research, 3(3), 803-816.

kontrplak, çağdaş inşa edilmiş çevreye ve yeniden kullanılan ahşap, atık ya da atılmış olana atıfta bulunur. Bileşik olarak bu üç materyal, cevap verdikleri toplulukların gelişim aşamalarından farklı olarak değil, yan yana durmaktalar. Bu anlamda Mitchell'in doğal çevrenin metalaştırılmasına (ve kaderine) dair sözler de Moran tarafından görselleştiriliyor (Aaron S.Moran online website, tarihsiz, Pave Paradise).

Moran yarattığı ahşap heykellerde, hem belirli bir bölgede bulduğu ahşap parçalardan esinlenmiş hem de onları direkt olarak kullanmıştır. Çalışmalarındaki materyal kullanımı ve bunu kentsel ve alt kent ile ilişkilendirmesini "Çalışmalarım, atılan materyalleri ve unutulan alanları, renk, kompozisyon ve materyal üzerine kurulu estetik bir deneyimle yeniden etkinleştirir. Hem kentsel hem de (alt) kent ortamlarında terk etme, geliştirme ve geçiş alanlarını ilgilendiren durumlarla ilgileniyorum. Yeniden kullanılan materyallere dayanarak, eserde doğal bir nostaljik kalite sıklıkla mevcuttur" sözleri ile özetler (Aaron S.Moran online website, tarihsiz, About).

Karayolları ve İki Yönlü Yollar (Piet Mondrian'in Broadway Boogie Woogie'sinden Sonra, adlı heykeline baktığımızda; çeşitli renk, doku ve desendeki ahşap parçaların bir araya getirildiğini görmekteyiz. Ki sanat eserine dönüşen ve bütünü oluşturan her bir parça, mekan-izleyici ve eser arasında bir diyalog yaratır. Burada materyalin yanı sıra geçmişe ait bir yapıtın tekrarlanmas1 da nostaljiye katkıda bulunur. Eşit olmayan renk, doku ve boyuttaki bu parçalar birbirleriyle eşleşir. Gelişigüzellik gibi görünse de Maron'un heykellerindeki her bir parça bir düzenin oluşmasına katkıda bulunur.

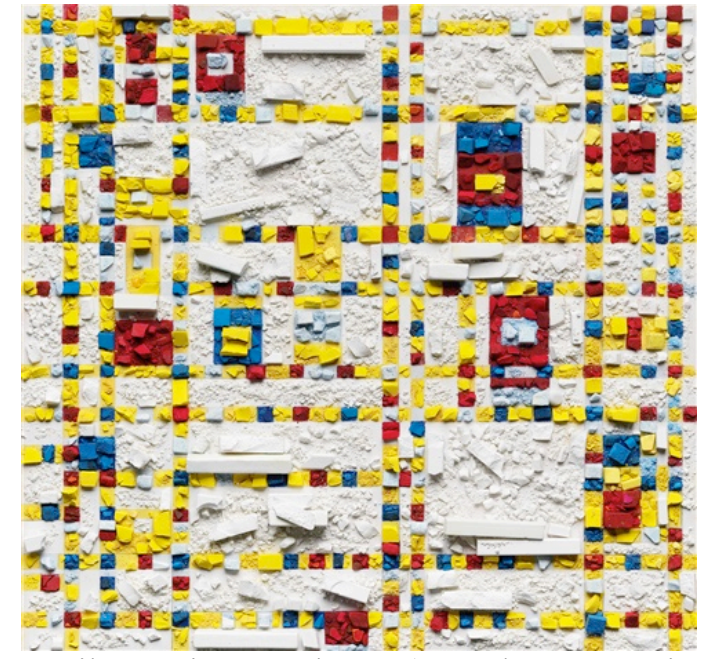

Resim 10. Vik Muniz, Metakrom (Broadway Boogie Woogie, Piet Mondrian'dan Sonra), 2016, Pigment bask1, 160 x $167 \mathrm{~cm}$

Birçok sanat yapıtını şeker, çikolata, elmas, havyar, oyuncak, delikler açılmış kâğıt, kuru pigment ve dergi parçaları gibi önemsiz görünen malzemeler ile tekrarlayan Vik Muniz (1961), izleyicinin zihninde tanıdık olan bu görüntüleri yeniden yapılandırmak için kullanır. Sanatçının da belirttiği gibi: "Bazen işlerin hangi malzemeler kullanılarak yapıldığını bilmek isterken, bazen de bunu bilmek istemiyoruz. Onun, bu Mondrian uyarlamasının da yer aldığı Metakrom (Metachrome) serisindeki çalışmalar, kinayede zengin bir içeriğe sahiptir. Eserin tam olarak içine gömülü olan pastel çubuklar, maddiyat meselesine meydan okuyorlar. Ve sonuçta elde edilen fotoğraf, sadece bir şeylerin imajı değil; boya ile ilgili çalışmalar, sanatın yaratılması 
veya rengin kendisi ile ilgili oluyor. Muniz'in Metakromları; çubuklar, kırıntılar ve pastel izlerinden oluşur. Bu malzemelerle Turner' dan parlak renklerin sınırlarını zorlayan Empresyonistlerin resimlerine kadar birçok ressamın resmini yeniden yaratır. Turner, Van Gogh, Stella, Rothko, Cézanne gibi sanatçılar için renk önemli bir uğraş iken, Muniz resim malzemelerine odaklanarak, izleyiciyi yapım ve boyanın temelini düşünmeye zorluyor. (Ben Brown Fine Arts Press Release, tarihsiz).

Mondrian'ın düz bir yüzeye sahip olan dikey ve yatayları, Muniz'in malzeme kullanımındaki farklılık ile bazı yerlerde bölünmelere uğruyor. Burada malzeme, hem resme bir materyal olarak hem de bir öğe olarak hizmet ediyor.

\section{Sonuç ve öneriler}

Mondrian'ın Broadway Boogie Woogie yapıtı bağlamında incelenilen tekrar yapıtların birçoğunun temelinde hayranlık, saygı vardır. Leon Polk Smith, Mondrian'ın köşeleri belirgin formları ve düz çizgilerinden etkilenmiş ve daha sonra bu çizgilere kendi eğri formlarını eklemiştir. Smith'in Mondrian'la ilişkisinde onun sanatsal tavrına ve resimlerinin alt yapısına duyduğu hayranlık yatar. Burgoyne Diller'ı da tekrara iten şey Smith ile benzerdir. Onun formu kullanma biçimi Diller'ı etkiler. Ve onun aksine çapraz ve üst üste binen dikdörtgenler konusunda katı bir tutum sergilemez. Diller'ın tekrarı Mondrian'la bir etkileşimin nihai sonucudur. Bir anlamda onlarınki karşılıklı bir alışveriştir. Mondrian'ın resmi ile benzerliğin yok denecek kadar az olduğu Alighiero Boetti ise ondan düz ve açık renkte bir yüzey üzerinde yer alan köşeleri belirgin renkli formları almayı yeğler. Ardından bu formları Mondrian'ın aksine simetrik bir düzende yerleştirir. Mondrian'ın resmi ile benzerliğin üst düzeyde olduğu bir yapıt üreten Tom Sachs ona olan hayranlığını gözler önüne serer. Bir Mondrian'a sahip olma ama aynı zamanda kendi olma (farklı malzeme ile tekrarlayarak) arasında kalarak bu yapıtı tekrarlar. Liu Ye ise Mondrian'ın resimlerini kendi kompozisyonun bir öğesi olarak düşünür. Mondrian tekrarları, onun özneleri ile ilişkisel bir bağ kurar. Resmin kendisinin yapıta dâhil olmasının yanı sıra Mondrian'1n geometri ve rasyonellik tavrı da onun resimlerinde kendini hissettirir. George Hadjimichalis, Mondrian'ın resmini, bu resmi yaratmasında etkili olan New York ve ürettiği ortam olan New York'taki atölyesi ile birlikte üç boyuta taşıarak tekrarlar. Bu tekrarlamayı da hayranlığın ya da saygının sonucu olarak okumak yanlış olmasa gerek. Aaron S.Moran ise Mondrian'ın dikey ve yataylarını farklı malzemeler ile oluşturur. Onun tekrarlama eyleminin altında da Mondrian'ın resimlerindeki rasyonellik ve geometri anlayışı yatar. Moran'ın tekrarları, orijinal ile benzerliğin en aza indirgenmiş halidir. Vik Muniz ise, Mondrian'ın resmi ile benzerliğin üst düzeyde olduğu bir yapıt üretir. Yakından bakıldığında farklı renkte pastel çubuklar ve toz ile karşılaşan izleyici için bu dokulu ve karmaşı yüzey, uzaklaştıkça dikey ve yatayların düzenine bürünür. Boyalardaki kırılmalar ve ufalanmalar, formların keskinliğini bozar, bazı yerlerde dağınıklık yaratır. Muniz'in tekrarının temelinde yatan ise, tanıdık görüntüyü farklı ve belki de sıradan bir malzeme ile yeniden üreterek izleyicinin karşına koyma ve onun tepkisini görme üzerinedir. Serkan Özkaya ise çağdaş sanatta bir yapıt üzerinden bir sorunsalı gündeme getirme tavrı ile hareket ederek, diğer tekrarlayan sanatçılardan farklı bir yaklaşım sergiler. İki farklı sanatçıyı aynı yapıt üzerinde birleştirerek orijinal ve kopya sorunsalını gündeme getirir.

Bir sanatçının elinden çıkmış olan bir yapıt; farklı sanatçılarca yeni bir dil, anlam ve üslupla tazelenir. Bazıları için, sanatsal tavırlarının oluşmasına katkı sağlayan bu yapıt, bazıları için hayranlık, bazıları için bir diyalog bazıları için ise sanat üzerine sorgulamalar adına seçilmiştir. 
Girgin, F. (2017). Repeats, "1 Artwork=9 Artworks". International Journal of Social Sciences and Education Research, 3(3), 803-816.

Sonuçta sanatta yapıt üzerinden tekrarlama eyleminin farklı gerekçelerle gerçekleştiğine tanık olmaktayı.

$\mathrm{Bu}$ araştırmada tekrarlar, Mondrian'ın Broadway Boogie Woogie adlı yapıtı bağlamında ele alınmıştır. Bu konuda inceleme yapmak isteyen araştırmacılar, farklı bir sanatçının yapıtını ya da aynı sanatçının farklı bir yapıtını seçebilirler. Her tekrarın altında farklı bir sebep yattığı ve her bir sanatçı farklı bir perspektiften o yapıta yaklaştığı için sonuç da farklı olacaktır. Bu farklılıkları görmek ve tekrarlamanın değiş̧ik boyutlarını incelemek adına yararlı olacaktır. Yine tekrarlama, resim sanatı dışında; edebiyat, tiyatro, sinema, müzik gibi farklı sanat dalları üzerinden de ele alınabilir.

\section{Kaynakça}

Aaron S.Moran online website. (tarihsiz). Pave Paradise. http://aaronsmoran.com/pave-paradise adresinden 10 Şubat 2017 tarihinde edinilmiştir.

Aaron S.Moran online website. (tarihsiz). About. http://aaronsmoran.com/about adresinden 10 Şubat 2017 tarihinde edinilmiştir.

Ben Brown Fine Arts Press Release. (tarihsiz). Vik Muniz Metachromes, 18 January- 11 March 2017. http://www.benbrownfinearts.com/usr/documents/exhibitions/press_release_url/112/vik-munizmetachromes-hk-press-release-.pdf adresinden 10 Şubat 2017 tarihinde edinilmiştir.

Buck, R. T. (2006). Leon Polk Smith American Original, Fred Jones Jr.Museum of Art the University of Oklahoma, 2006, 9-20. leonpolksmithfoundation.org/research-resources/selected-essays-reviews/ adresinden 10 Temmuz 2015 tarihinde edinilmiştir.

Enright, R., Walsh, M. (2014, June). Doing Just the Right Wrong Thing: An Interview with Tom Sachs, Bordercrossings, Issue 130, http://bordercrossingsmag.com/article/doing-just-the-right-wrong-thing adresinden 10 Temmuz 2015 tarihinde edinilmiştir.

Kortun, V., Kosova, E. (2007, Haziran 28). Ofsayt Ama Gol. http://www.oocities.org/guncelsanat/cobcg.htm adresinden 11 Temmuz 2015 tarihinde edinilmiş̧ir.

Lynton, N. (1982). Modern Sanatın Öyküsü, çev.Cevat Çapan, Sadi Öziş. İstanbul: Remzi Kitabevi Yayınları.

Parks, A. ( 1986, February). Life Line, Leon Polk Smith, Arts Magazine 60, Number.6, 26-27, leonpolksmithfoundation.org/research-resources/selected-essays-reviews/ adresinden 10 Temmuz 2015 tarihinde edinilmiş̧ir.

Prinz, I. (tarihsiz). Drawings\&Collages by Burgoyne Diller Pioneer of Minimalism, October 6 to November 5, 2011, Spanierman Modern Online Catalogue, http://spaniermanmodern.com/PDF-cataloguesbooks/Burgoyne-Diller-Drawing-Collages_web.pdf adresinden 11 Nisan 2016 tarihinde edinilmiştir.

Sperone Westwater Press Release. (tarihsiz). Alighiero Boetti, Untitled-Victoria Boogie Woogie. 1972, 19 April-2 June 2001, Sperone Westwater, New York, www.speronewestwater.com/exhibitions/alighiero-e-boetti_1/installations adresinden 10 Temmuz 2015 tarihinde edinilmiştir.

Sperone Westwater Press Release. (tarihsiz). Liu Ye "Temptations" 14 September - 28 October 2006. http://images.speronewestwater.com/www_speronewestwater_com/Liu_Ye_Press_Release_2006.pdf adresinden 5 Nisan 2017 tarihinde edinilmiştir.

Whitney Museum of American Art, Collection. (tarihsiz). Burgoyne Diller, Third Theme, 1946-48, http://collection.whitney.org/object/51 adresinden 13 Temmuz 2015 tarihinde edinilmiştir. 
Girgin, F. (2017). Tekrarlar, "1 Yapit=9 Yapit". International Journal of Social Sciences and Education Research, 3(3), 803-816.

Wilton, K. (2009, November 13). Liu Ye, The Al Interview, artinfo.com, Sperone Westwater, http://images.speronewestwater.com/www_speronewestwater_com/LiuYeArtinfo13Nov2009.pdf adresinden 15 Mart 2017 tarihinde edinilmiştir.

\section{Resim Listesi}

Resim 1. Piet Mondrian, Broadway Boogie Woogie, https://en.wikipedia.org/wiki/Broadway_BoogieWoogie adresinden 7 Temmuz 2015 tarihinde edinilmiştir.

Resim 2. Leon Polk Smith, Victory Boogie-Woogie’ye Sayg1 1, http://leonpolksmithfoundation.org/artwork/1940s/ adresinden 7 Temmuz 2015 tarihinde edinilmiştir.

Resim 3. Burgoyne Uiller, Üçüncü Tema, lhttp://whitney.org/image_columns/0023/7175/58.58_diller_800.jpg adresinden 13 Temmuz 2015 tarihinde edinilmiştir.

Resim 4. Alighiero Boetti, İsimsiz- Victoria Boogie Woogie, http://www.speronewestwater.com/artists/alighiero-boetti\#7 adresinden 7 Temmuz 2015 tarihinde edinilmiştir.

Resim 5. Tom Sachs, Victoria Boogie Woogie, http://tomsachs.org/work/victory-boogie-woogie adresinden 7 Temmuz 2015 tarihinde edinilmiştir.

Resim 6. Serkan Özkaya, Broadway Boogie Woogie, http://www.serkanozkaya.com/images/projects/dearsi/2-moma-broadway_larger.jpg adresinden 11 Temmuz 2015 tarihinde edinilmiştir.

Resim 7. Liu Ye, Bir Zamanlar Broadway’de, http://www.speronewestwater.com/artists/liu-ye\#14 adresinden 5 Nisan 2017 tarihinde edinilmiştir.

Resim 8. George Hadjimichalis, New York'ta Piet Mondrian'in Stüdyosu, https:/www.flickr.com/photos/33458656@N06/4762130224/ adresinden 7 Temmuz 2015 tarihinde edinilmiştir.

Resim 9. Aaron S.Moran, Karayolları ve İki Yönlü Yollar (Piet Mondrian'ın Broadway Boogie Woogie'sinden Sonra), http://aaronsmoran.com adresinden 10 Şubat 2017 tarihinde edinilmiştir.

Resim 10. Vik Muniz, Metachrome (Broadway Boogie Woogie, Piet Mondrian'dan Sonra), http:/www.artnet.com/artists/vik-muniz/metachrome-broadway-boogie-woogie-after-piet-a0L7KGRovuJFJHErtX5p86A2 adresinden 10 Şubat 2017 tarihinde edinilmiştir. 


\section{Extended abstract in English}

Repetition is simply an action that enables a learner to achieve or increases its permanence. We need to repeat things, for example to learn things like swimming, language, driving a car, or to make our learnings permanent. In the process of harmonization with nature, repetitions also come into play when some vital tools are created. From the moment a tree, stone, or bone is found to be similar to something else and functioning, the person decides to repeat it and make another one and one more. In fact, we can say that it constitutes the functional dimension or origin of the craft. However, this situation changes slightly in the art. The drawings made by the first people on the wall are similar to those in nature. But it is not the same. These drawings are now regarded as the first trends of art. After this process we can evaluate the actions of individuals who do not have art consciousness; The individuals who have art consciousness are good, why do they need repetition?

Most of the artists, especially those who are up to the modern turnover, touring museums, drawing drawings from the sculptures they examine, often choose to recreate that work, such as the curiosity of what is special, the desire to educate the eye, the desire to acquire skills, Here again, it enters into art with 'learning' purpose just as it is in human social life. However, very rarely such a reason lies in the repetitive action that starts to be seen in modern art and increases its effectiveness in contemporary art. An artwork is expressed in different language, meaning, technique and style, and the same expressions are being renewed. In this deliberate repetition process, the artist starts to work with choice. It has a network of relationships in which to choose a work to pass through its own thought filter, such as his/her bond with artwork, having a similar inner world or being fit to enter into a different reckoning. We are faced with so many similarities in the age we are living, that perhaps it is inevitable that this resemblance to nature and the act of differentiation through similar. Or the effort to speak more of contemporary art becomes one of the reasons underlying the repetition of the artworks.

If we think that each artist passes through a different life and artifice as an individual; It should not be surprising that a selection of works starting with a work will result in a different work as long as it is not an exact duplicate. In this research, Mondrian's work "Broadway Boogie Woogie" was based in order to better understand the transformation of artworks, the reasons why artists choose a work, and what different things they say through an artwork.

There is admiration and respect on the basis of many of the recreated artworks examined in the context of Mondrian's work on Broadway Boogie Woogie. Leon Polk Smith was influenced by Mondrian's distinctive forms and straight lines, and then added their own curved forms to these lines. In relation to Mondrian, Smith admires his artistic attitude and his admiration for the background of his paintings. The reason why Burgoyne Diller is pushing back is similar to Smith. His way of using the form affects Diller. And, on the contrary, it does not show a solid attitude about the rectangles that cross and overlap. Diller's repetition is the ultimate result of an interaction with Mondrian. In a sense, theirs is a mutual exchange. Alighiero Boetti, whose work is little similar to Mondrian's painting, likes to take clear colored forms from angles on a flat and light surface. Then he places these forms on a symmetrical plane, unlike Mondrian. Tom Sachs, who produces an artwork that is similar to Mondrian's painting, shows his admiration. It repeats this work by staying between having a Mondrian but also being self (repeating with different material). Liu Ye considers Mondrian's paintings as a form of his composition. The Mondrian repetitions establish a relationship with his subjects. In addition to being included 
in the structure itself, Mondrian's geometry and rationalism also manifest itself in his paintings. George Hadjimichalis repeats Mondrian's painting in three dimensions, together with the workshop in New York and New York, which was influential in creating this painting. It is not wrong to read this repetition as a result of admiration or respect. Aaron S. Moran creates Mondrian's vertical and horizontal with different materials. Underneath his repetitive action is also the understanding of the rationality and geometry of Mondrian's paintings. Moran's repetitions are the most degraded version of the original. Vik Muniz produces an artwork that is similar to Mondrian's painting. From a close look, this textured and complex surface for the viewer who is encountering pastel bars and powder with different colors takes the order of vertical and horizontal as they move away. Breaking and crumbling in the paint breaks the sharpness of the forms and creates scattering in some places. What lies at the base of Muniz's repetition is about putting the familiar image back into the viewer by reproducing it with a different and perhaps ordinary material, and seeing his reaction. Serkan Özkaya, on the other hand, behaves differently from other recurrent artists by acting with a problematic agenda through a work in contemporary art. Combining two different artists on the same work brings the original and copy problem to the agenda.

An artwork of an artist; different artists refreshed with a new language, meaning and style. For some, this work, which contributed to the formation of his artistic attitudes, has been selected for admiration for some, dialogue for some, and inquiry for art. As a result, we are witnessing the fact that repetition through art works in different ways. 